\title{
Estimation of Significant Wave Heights from X-Band Radar Using Artificial Neural Network 인공신경망을 이용한 X-Band 레이다 유의파고 추정
}

\author{
Jaeseong Park*, Kyungmo Ahn**, Chanyeong Oh*** and Yeon S. Chang**** \\ 박재성* . 안경모** . 오찬영*** . 장연식****
}

\begin{abstract}
Wave measurements using X-band radar have many advantages compared to other wave gauges including wave-rider buoy, P-u-v gauge and Acoustic Doppler Current Profiler (ADCP), etc.. For example, radar system has no risk of loss/damage in bad weather conditions, low maintenance cost, and provides spatial distribution of waves from deep to shallow water. This paper presents new methods for estimating significant wave heights of X-band marine radar images using Artificial Neural Network (ANN). We compared the time series of estimated significant wave heights (Hs) using various estimation methods, such as signal-to-noise ratio $(\sqrt{S N R})$, both $\sqrt{S N R}$ and the peak period $\left(T_{P}\right)$, and ANN with 3 parameters $\left(\sqrt{S N R}, T_{B}\right.$ and $\left.R_{v a l>k}\right)$. The estimated significant wave heights of the X-band images were compared with wave measurement using ADCP(AWC: Acoustic Wave and Current Profiler) at Hujeong Beach, Uljin, Korea. Estimation of Hs using ANN with 3 parameters $\left(\sqrt{S N R}, T_{B}\right.$ and $R_{\text {val }>k}$ ) yields best result.
\end{abstract}

Keywords : X-band radar, significant wave heights, machine learning, artificial neural network (ANN), peak period

요 지 : 항해용 X-band 레이다를 이용한 파랑관측은 기존의 파랑관측 방법인 부이식 파고계, 압력식 파고계, 초음 파식 파고계에 비해 많은 이점이 있다. 예를 들면 유실과 파손의 위험이 없고, 유지관리 비용이 적게 들며, 심해 부터 천해까지 파랑의 공간적 분포를 알 수 있다. 본 논문에서는 레이다형 파고계의 유의파고 측정 정확도를 높이 는 인공신경망을 이용한 알고리즘을 제시하였다. 레이다형 파고계에서 유의파고를 추정하는 전통적인 방법은 신호 대 잡음 비율 $(\sqrt{S N R})$ 또는 신호 대 잡음 비율과 첨두주기 $\left(T_{P}\right)$ 를 이용하는 방법이 있다. 본 연구에서는 신호 대 잡 음 비율, 첨두주기 및 레이다 이미지 해상도 비율 $\left(R_{v a l>k}\right)$ 을 입력변수로 하는 인공신경망 알고리즘을 이용하여 유의 파고 추정의 정확도를 향상시켰다. 개발된 알고리즘을 울진 후정해수욕장에서 초음파식 파고계로 측정한 유의파고 의 시계열과 비교하여 정확도 향상을 확인하였다.

핵심용어 : X-band 레이다, 유의파고, 머신러닝, 인공신경망, 첨두주기

\section{Introduction}

\subsection{Motivation}

Due to the utilization of coastal and offshore spaces and the need for designing structures on coastal areas, important external forces must be considered, including wave information such as wave heights, wave periods, and wave directions. It is essential to know these wave parameters in many coastal engineering applications for the protection and restoration of the nearshore environments such as beaches and natural habitats.

With newly developed technologies, the hardware specifications for wave gauges are being upgraded. Especially, nautical radar wave gauges have improved their accuracy due to improved hardware and software performances. Alpers and Hasselmann (1982) introduced an estimation of significant wave heights by regression of energy spectra using SAR (Synthetic Aperture Radar). Instead of SAR, Young et al. (1985) were the first to utilize X-band nautical radar for estimating significant wave heights. There have been many

\footnotetext{
*Graduate Student, Dept. of Spatial Design \& Eng., Handong Global University

**Professor, School of Spatial Environment System Engineering/Research Institute of Floating Offshore Wind-power Generation Farm Field, Handong Global University(Corresponding author: Kyungmo Ahn, Handong-ro, 558, Pohang, Kyeongbuk 37554, Korea, Tel: +82-54-260-1421, kmahn@handong.edu)

***Associate Research Engineer, Institute of Construction \& Environmental Research, Handong Global University

****Principal Research Scientist, Maritime ICT R\&D Center, Korea Institute of Ocean Science and Technology
} 
Table 1. Comparison of various wave gauges in economic and functionality point of views

\begin{tabular}{|c|c|c|c|c|}
\hline & \multicolumn{3}{|c|}{ Point measurement } & \multirow{2}{*}{$\begin{array}{c}\text { Area measurement } \\
\text { Radar }\end{array}$} \\
\hline & Buoys & P-u-v gauge & ADCP & \\
\hline Accuracy & high & medium high & high & medium \\
\hline Durability & low & medium high & medium high & very high \\
\hline Initial cost & high $(\$ 80,000)$ & low $(\$ 25,000)$ & low $(\$ 30,000)$ & very high $(\$ 120,000)$ \\
\hline Maintenance cost & high & medium & medium & very low \\
\hline Water depth & $20 \sim 100 \mathrm{~m}$ & $<20 \mathrm{~m}$ & $<50 \mathrm{~m}$ & No limitation \\
\hline Spectrum & frequency & frequency & frequency & frequency \& wavenumber \\
\hline Currents & no & bottom currents & current profile & surface currents \\
\hline Data transmission & direct & $\begin{array}{c}\text { data link to } \\
\text { shore }\end{array}$ & $\begin{array}{c}\text { data link to } \\
\text { shore }\end{array}$ & direct in real time \\
\hline
\end{tabular}

studies for improving the performance of wave gauges using $\mathrm{X}$-band marine radar (nautical radar). However, the accuracy of wave heights measured by X-band radar is relatively low compared to other wave gauges. Therefore, further research is needed to improve the accuracy of X-band marine radar.

\subsection{Review of wave gauges}

Wave gauges have two categories of methods for measuring waves. Point measuring type of wave gauge is waverider buoys, $\mathrm{P}-\mathrm{u}-\mathrm{v}$ (pressure and $\mathrm{u}-\mathrm{v}$ velocity) gauge and ADCP (acoustic doppler current profiler), etc. Measuring waves over a sea surface area can be done with a radar. Buoys, P-u-v gauges, and ADCP measure wave surface elevations directly at sea, while radio detecting and ranging (radar) measures waves through remote sensing using microwaves. The results from each wave gauge are not the same but similar because the steady-state sea has ergodicity. Ergodicity means that the distribution in one place over time has the same behavior as the spatial distribution in a fleeting moment. Therefore, wave information obtained from the point measurement and the area measurement is assumed to be the same under steady ergodic condition.

Table 1 shows the characteristics of wave gauges. Waverider buoy, P-u-v gauge and, ADCP have high accuracy compared to radar and initial installation costs are lower than that of radar system. Even though radar wave gauge has a low accuracy in wave height measurement but has many advantages. Radar wave gauge has low life cycle cost not only because the durability is very high but also because maintenance costs are very low compared to other wave gauges. Additionally, as radar can measure waves remotely depending on the distance from the radar system, it can measure waves without any limitations of water depth including very shallow water depth such as surf zone as well as deep water. Importantly, radar can measure waves together with sea surface current velocity and wave number spectrum. Radar can also obtain wave information directly in real time.

\section{Estimation of Significant Wave Heights}

\subsection{Process of estimating significant wave heights}

The received radar signal is not the direct information about the actual height of the wave, but the distribution of the energy intensity received by the radar signal scattered by the waves. Therefore, it is necessary to estimate the measured radar signal to get wave information correctly. Alpers and Hasselmann (1982) presented the algorithm for calculating the signal to noise ratio from SAR images to estimate significant wave heights. Nieto et al. (2004) showed the detail of the algorithm and introduce MTF (Modulation Transfer Function) to estimate significant wave heights from the X-band marine radar deployed in the field.

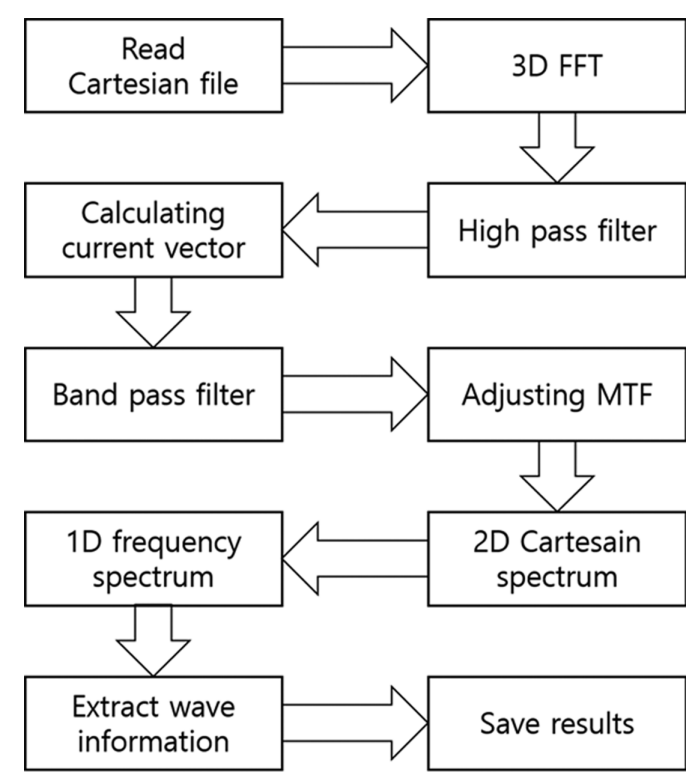

Fig. 1. Process of determining wave information from the radar images. 
Fig. 1 shows the process of estimating wave information. Time series of sea surface images in the form of Cartesian coordinates are analyzed to get 3 dimensional image spectrum through 3D fast Fourier transform (3D FFT). Then, the current vector is calculated after high pass filtering. By applying the pass band filter based on the wave dispersion equation, we can obtain the $3 \mathrm{D}$ wave spectrum. Integration of the 3D wave spectrum over frequency yields the 2 dimensional wave number spectrum. Applying proper MTF, we can obtain wave number spectrum. We can also derive the wave frequency spectrum as well as directional wave frequency spectrum by the transformation of coordinates. From the wave frequency and directional frequency spectrum, we can extract wave information such as significant wave heights, peak period, and mean wave direction, etc.

\subsection{Signal-to-noise ratio}

The major signal components of the radar system are the target, clutter, and noise. In a general case, the radar has a target, such as a ship or an airplane. However, X-band radar wave gauge systems use sea clutter for analyzing wave parameters such as the significant wave height and peak period. Alpers and Hasselmann (1982) defined the sea clutter as the 'signal', other clutter as 'clutter'and noise as 'thermal noise'.

Alpers and Hasselmann (1982) estimated significant wave heights with synthetic aperture radars by separating the wave signal from background noise, so-called 'signal to noise ratio' (SNR). The SNR can be used to determine significant wave heights with linear regression as in Eq. (1).

$$
H_{s}=A+B \sqrt{S N R}
$$

The SNR is determined by separating the spectral components using the dispersion relation. Nieto (2000) represents the SNR as follows:

$$
S N R=\frac{\int_{\Omega_{k, \omega}} F^{(3)}\left(k_{x}, k_{y}, \omega\right) d k_{x} d k_{y} d \omega}{\int_{\Omega_{k, \omega}} F_{b g n}^{(3)}\left(k_{x}, k_{y}, \omega\right) d k_{x} d k_{y} d \omega}
$$

where $F^{(3)}\left(k_{x}, k_{y}, \omega\right)$ is the power spectral density filtered by the dispersion relation, $F_{b g n}^{(3)}\left(k_{x}, k_{y}, \omega\right)$ is the power spectral density outside the dispersion relation.

\subsection{Peak period}

The estimation of significant wave heights using SNR and peak period has been proposed by Ahn et al. (2014) and

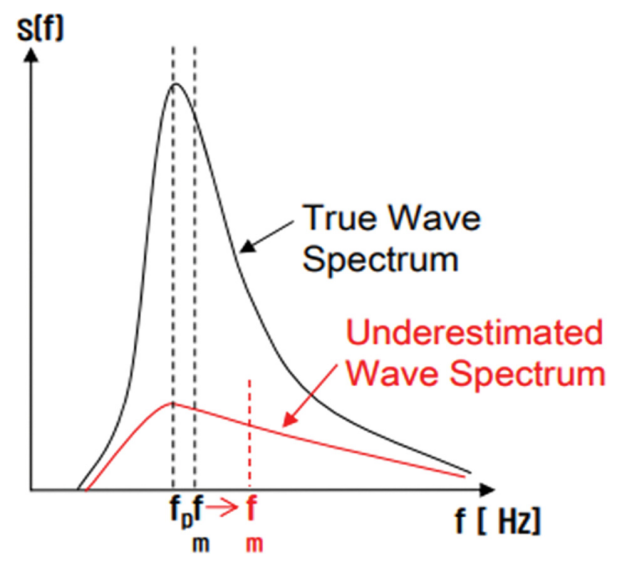

Fig. 2. Differences in the spectrum obtained from the radar and true spectrum of the smooth surface swells.

Ahn et al. (2015). A case with low energy reception due to low energy backscattering of smooth surface waves is considered to significantly underestimate the significant wave height. It is because of the absence of ripples that are generated by local wind. Smooth sea surfaces of swell waves without ripples mean no Bragg resonance occurred and result in weak backscattered signals. As a result, the radar signal is not enough for an analysis of wave heights by using $\sqrt{S N R}$ only. Fig. 2 shows the underestimated frequency spectrum of low energy reception case such as smooth surface swell waves. However, the peak frequency of an underestimated wave spectrum is usually identical to the true wave spectrum of swells. On the other hand, the mean frequency of the observed energy spectrum is usually higher than the mean frequency of the true spectrum. Therefore, proper calibration of significant wave heights could be achieved by including peak frequency information.

\subsection{Artificial neural network}

ANN (artificial neural network) is a method of finding the output of each neuron by some nonlinear function of the sum of its inputs. In nature, each piece of data has no exact linear regression. Although there are multiple methods of regressions, it is difficult to generalize expressions for a formalized regression in the case of a complex model. ANN can help solve this problem.

The input data for a neural network includes the connections between neurons. After processing input data, the networks produce their output data. Comparing between the output data and target data, the network adjusts its own weighting. This process continues until the satisfying conditions, such as the error, are lower than a specific constant or the number of iterations exceeds a specific constant. The 
structure of a neuron is expressed in various ways depending on the type of input and neuron.

The ANN process consists of two parts. The first is training the data and the second is simulating the data. In the training part, the dataset is preprocessed as input variables. Next, the ANN network is created, which is a feedforward backpropagation network with a tangent-sigmoid transfer function in a hidden layer and a linear transfer function in the output layer. By using the data and the network, the network is trained for estimating the target value. After the training, the output weights, bias, and other conditions are saved from the trained network. The next part is to simulate a dataset using the trained network.

\subsection{Estimation of significant wave heights from $X$ - band radar data at Uljin}

We compared the results of different estimation methods applied to the data obtained at Hujeong Beach, Uljin which is located on the east coast of the Korea peninsula.

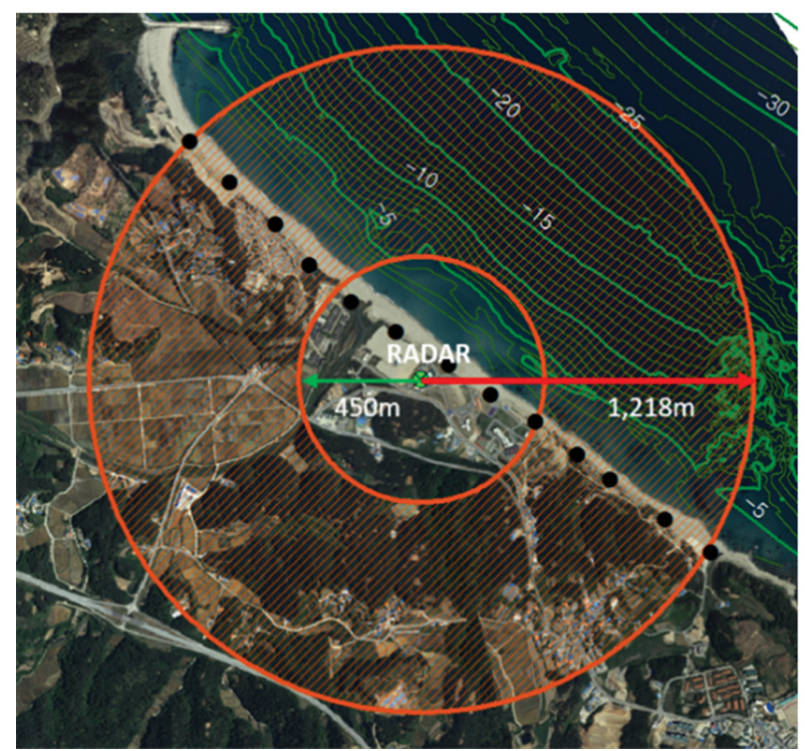

The radar was stationed at a height of $20 \mathrm{~m}$ above sea level and scanned sea surfaces of radius from $450 \mathrm{~m}$ to $1,218 \mathrm{~m}$ as is shown in Fig. 3. The shoreline of Hujeong Beach stretches from the northwest to the southeast. Therefore, waves coming from the northeast are frequently observed. The data used for the analysis had been obtained from December 15 to December 23, 2014. In every 20 minutes, the radar, which was rotating at $24 \mathrm{rpm}$, acquired 32 polar images and the time interval of each image is $2.5 \mathrm{sec}-$ onds. The radar was rotating for 80 seconds in every 20 minutes.

Fig. 3 shows a polar radar image obtained at 12:50 pm on December 18, 2014. In the figure, the red circle is the location of the Acoustic Wave and Current Profiler (AWAC) of Nortek deployed at water depth of $18.7 \mathrm{~m}$ and the red star represents a waverider buoy deployed at water depth of $32.0 \mathrm{~m}$. The red dotted rectangle in the figure is a Cartesian image used for estimating significant wave heights and other wave parameters. The center of the Cartesian image is

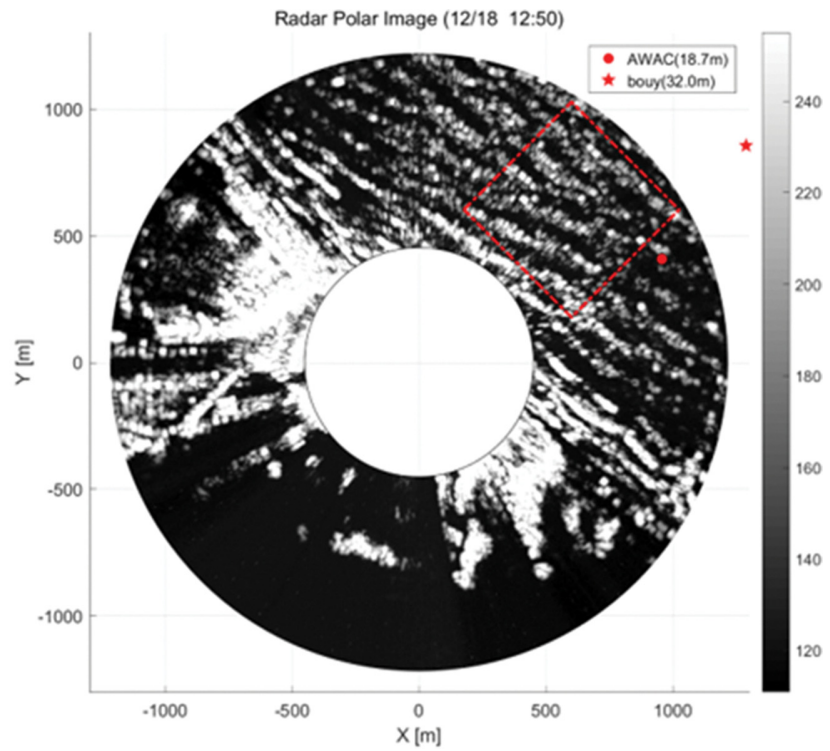

Fig. 3. (left) Radar system deployed at Hujeong Beach, Uljin, (right) Radar polar image at 2014/12/18 12:50.

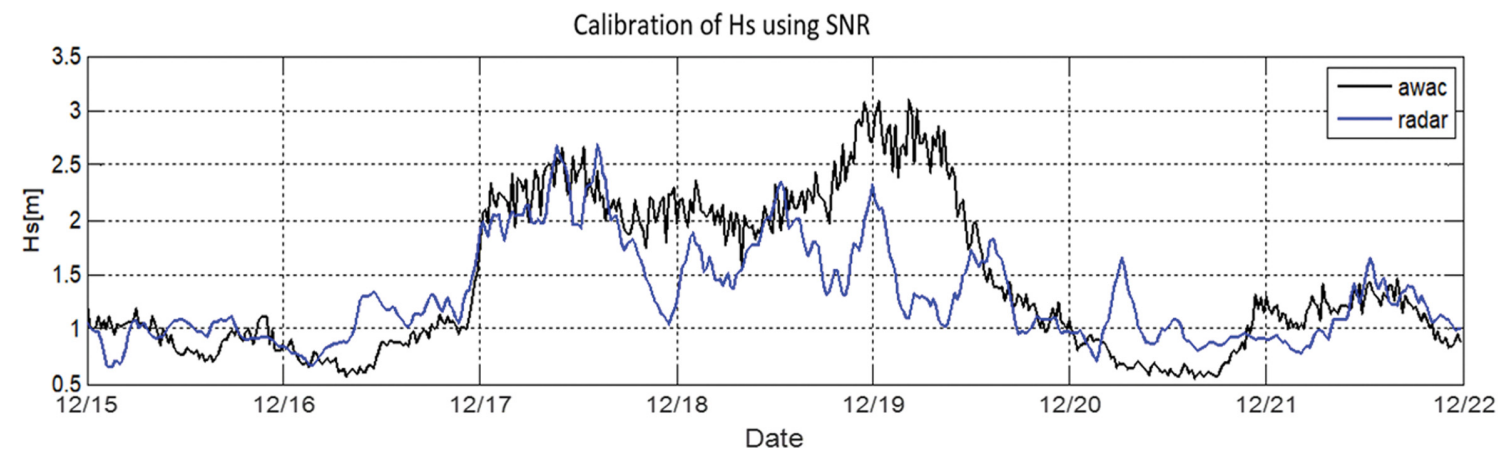

Fig. 4. Time series of significant wave heights estimated by using $\sqrt{S N R}$. 
$850 \mathrm{~m}$ away from the radar with dimensions of $600 \mathrm{~m} \times$ $600 \mathrm{~m}$.

Fig. 4 shows time series of significant wave heights estimated by $\sqrt{S N R}$ during winter storm. From 12/17 22:00 to 12/19 12:00, the estimated significant wave heights from the radar are significantly underestimated after 20/18 18:00. This is because of the absence of ripples due to weak local wind velocity, which affects weak Bragg resonance condition.

Fig. 5 shows polar radar images during the storm in 2017. Both polar images in the figure have similar significant wave heights of $2.28 \mathrm{~m}$ and $2.03 \mathrm{~m}$ according to AWAC measurement, but radar images have very different sea sur-

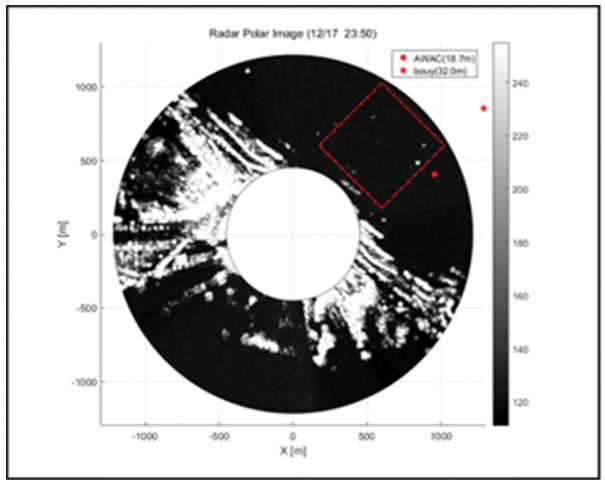

a. When Wind Speed Is Low

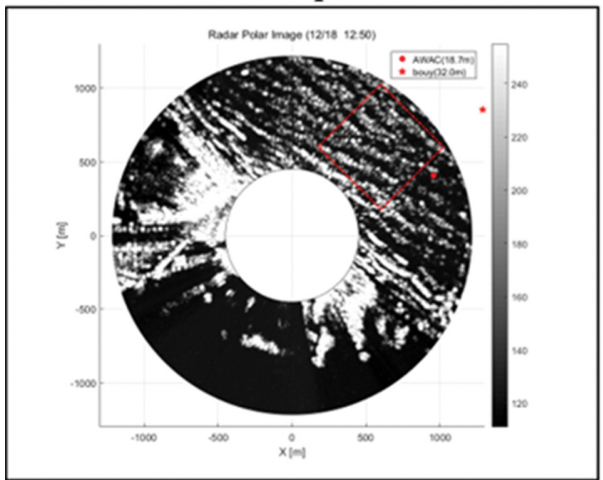

b. When Wind Speed Is High face undulations and estimated significant wave heights of $1.05 \mathrm{~m}$ and $2.15 \mathrm{~m}$, respectively. The reason for this discrepancy is that local wind is not blowing enough to make ripples on the surface of the waves and thereby cause weak backscattering of signals at the time of measurement. Wind information, including not only the speed but also direction, is important for backscattering to occur. As shown in the figure, red dot lines A and B drawn in wind velocity stick and significant wave heights estimated from radar images are $1.05 \mathrm{~m}$ and $2.15 \mathrm{~m}$, respectively. Red dot line A is the case where the wind direction is from land to sea and wind speed is very weak. However, Red dot line B is the
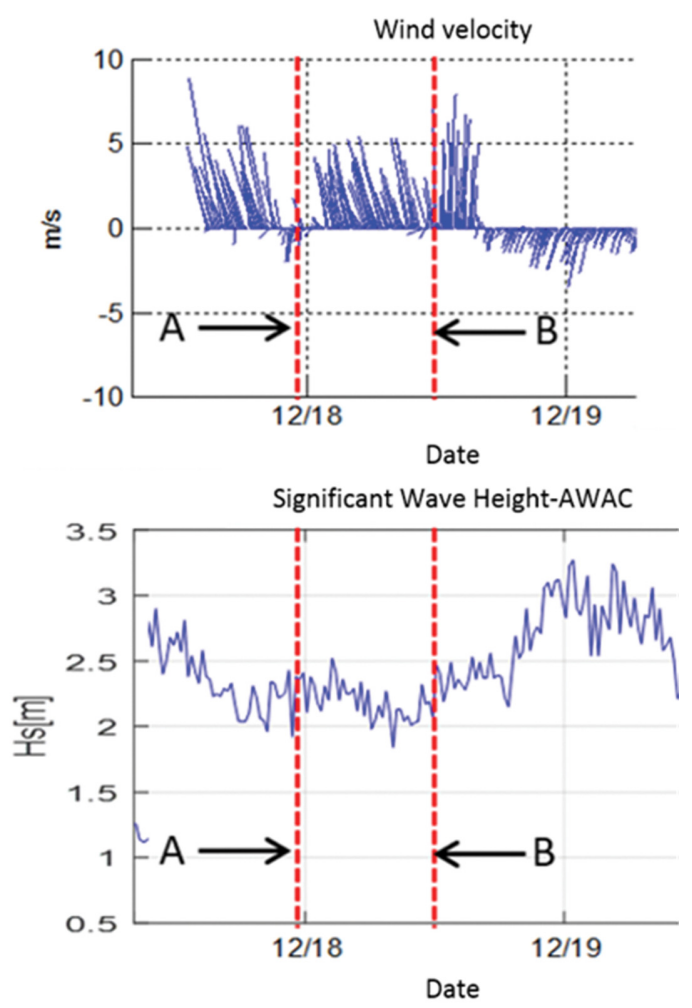

Fig. 5. Radar polar images when the wind speed is low at 12/17 23:50 (left top)and high at 12/18 12:50 (left bottom), and the time series of the wind velocities (right top) and the time series of the significant wave heights obtained from the AWAC.

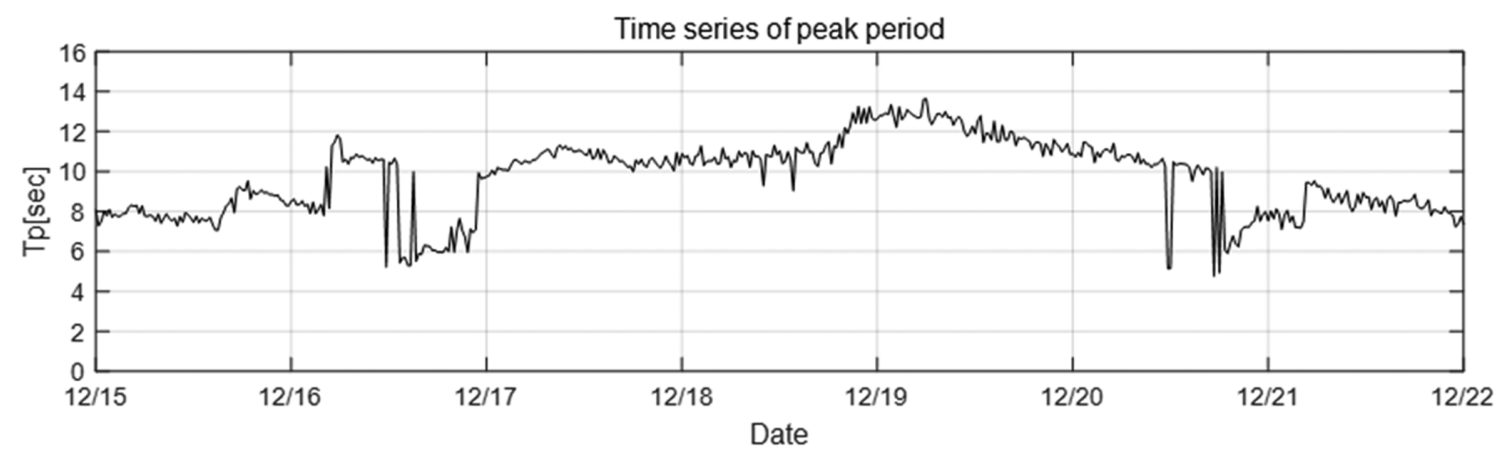

Fig. 6. Time series of peak periods obtained from the AWAC. 
case where the wind direction is from sea to land and wind speed is high enough to make ripples for Bragg resonance to occur.

Fig. 6 shows the time series of peak periods $\left(T_{p}\right)$ obtained from the AWAC. As is shown in the figure, peak periods are greater than $10 \mathrm{sec}$ from the beginning of winter storm and maintained its period even after the storm. During the storm, wave heights are varying but the variation of peak periods is relatively small. It is because wave periods are considered to be influenced by the wave travelling distance but not by local wind. Wind waves are caused by local wind, but swell waves are propagated from distant seas. Therefore, a swell is related neither to the local wind speed nor to the wind direction. In order to calibrate wave heights from radar images which are influenced by local wind speed and direction, it may be good to use peak periods to compensate for the underestimated significant wave heights.

To use the peak period data, catching the peak periods accurately is important in radar images. Fig. 7 shows the radar polar image obtained at 2014/12/17 23:50. The red dotted rectangular ' $\mathrm{B}$ ' area is the target Cartesian region to calculate wave parameters from the radar. In this area, the Cartesian image does not show enough radar signal to obtain the wave information. However, the radar image in the 'A' area where breaking waves occurred near the coastline, is an adequate place to obtain wave peak period. As far as nonlinear interactions of wave frequency components are not dominant, peak wave periods are identical in regions $\mathrm{A}$ and $\mathrm{B}$. Therefore, we programmed to choose the region whenever we need to obtain necessary wave parameters such as wave period.

Fig. 8 show a comparison of significant wave heights from the AWAC and those estimated from radar by consid-

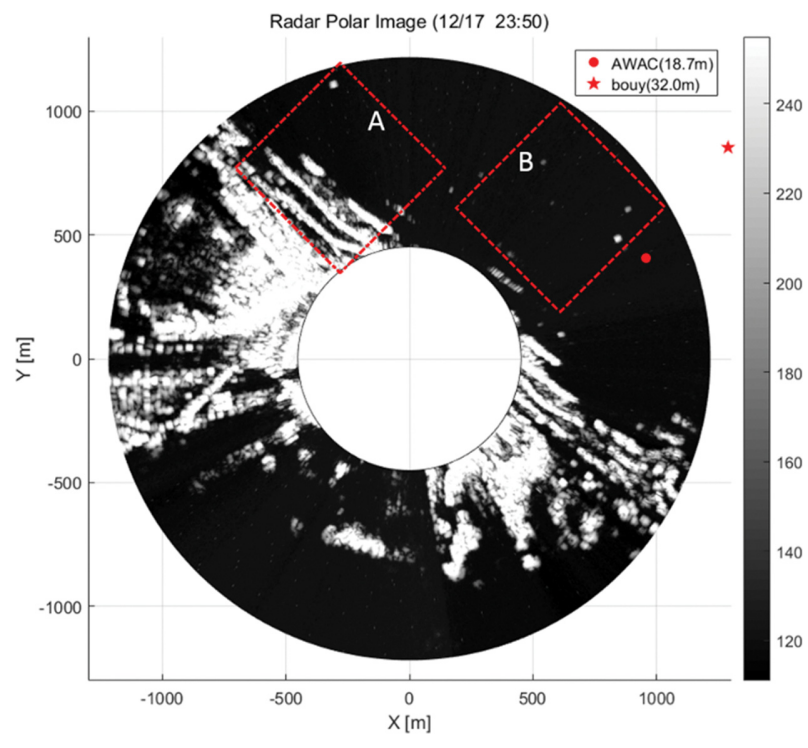

Fig. 7. Radar polar image obtained at 2014/12/17 23:50.

ering $\sqrt{S N R}$ and $T_{P}$. These results have a RMSE (root mean square error) of $0.29 \mathrm{~m}$, a maximum error of $0.99 \mathrm{~m}$ and an $R^{2}$ (coefficient of Determination) of 0.79 . These results are more accurate than those estimated using $\sqrt{S N R}$ only as is shown in Fig. 4.

Estimation using an ANN is used for improving the accuracy of estimating significant wave heights. Fig. 9 shows the structure of the ANN to make the feedforward backpropagation network. The input vector uses the parameters $\sqrt{S N R}, T_{P}$ and $R_{\text {val } / k}$.

Parameter $R_{\text {vall }}$ is used to represent wind condition which is defined as

$$
R_{\text {val } / k}=N_{u} / N_{t}
$$

where $N_{u}$ is the number of pixels higher than the $k$ value in the target image. $\mathrm{N}_{t}$ is the number of pixels in the target

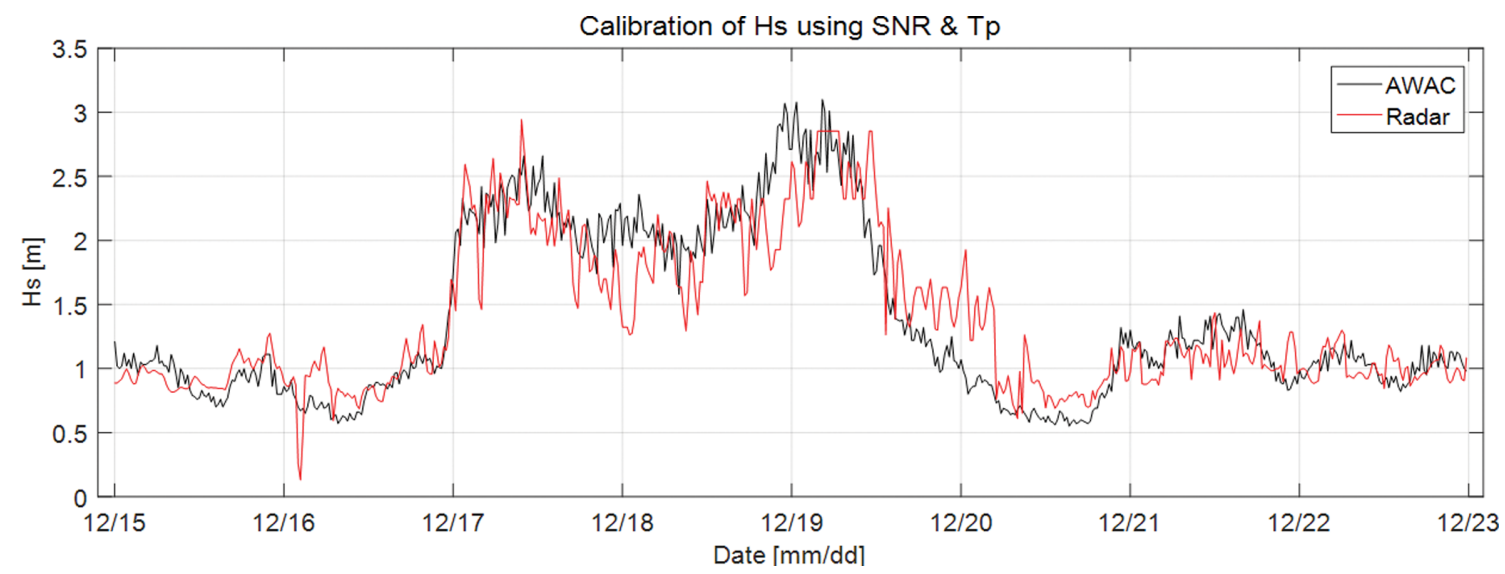

Fig. 8. Time series of the estimated significant wave heights using $\sqrt{S N R}$ and $T_{P}$ of the radar images and compared with significant wave heights obtained from the AWAC. 


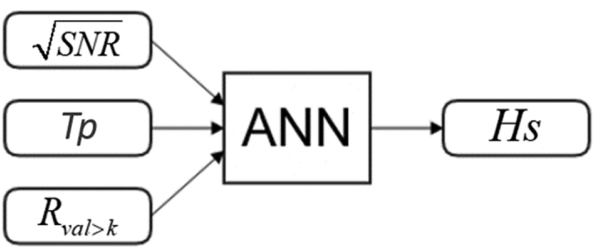

Fig. 9. Structure of the ANN process with input vectors $\sqrt{S N R}, T_{P}$ and $R_{\text {valk }}$.

image.

Fig. 10 shows the variation of $R_{\text {valk }}$ which is almost zero when there are not much ripples on the sea surface. This condition occurs when the wind is blowing from land to sea direction or no local wind exists.

The ANN used for Hs learning consists of an input layer, a hidden layer, and an output layer. In this study, The number of neurons in the hidden layer was 10. Levenberg-Marquardt was used for the ANN learning method, and the tangent-sigmoid function was used for the transfer function. The total number of radar data used in the analysis is 576. The number of ANN training dataset is 144 which is uniformly sampled from total data. In the training, $70 \%$ of the training data was used for training, $15 \%$ for verification and the remaining $15 \%$ for testing, and it was randomly sampled.

Fig. 11 shows the results of the estimated significant wave heights using ANN compared with those obtained from AWAC. These results have an RMSE of $0.22 \mathrm{~m}$, a maximum error of $0.80 \mathrm{~m}$ and $R^{2}$ of 0.89 . The RMSE and the maximum error of the results using ANN is improved by $0.07 \mathrm{~m}$ and $0.19 \mathrm{~m}$, respectively, compared to the result obtained using $\sqrt{S N R}, T_{P} R^{2}$ is also increased by 0.10 .

\section{Conclusion}

The primary purpose of the present study is to improve the accuracy of estimation of significant wave heights observed by X-band marine radar. We have tested our estimation methods of significant wave heights $\left(H_{s}\right)$ using ANN at Hujeong Beach, Uljin.

The radar was stationed at the height of $20 \mathrm{~m}$ above sea

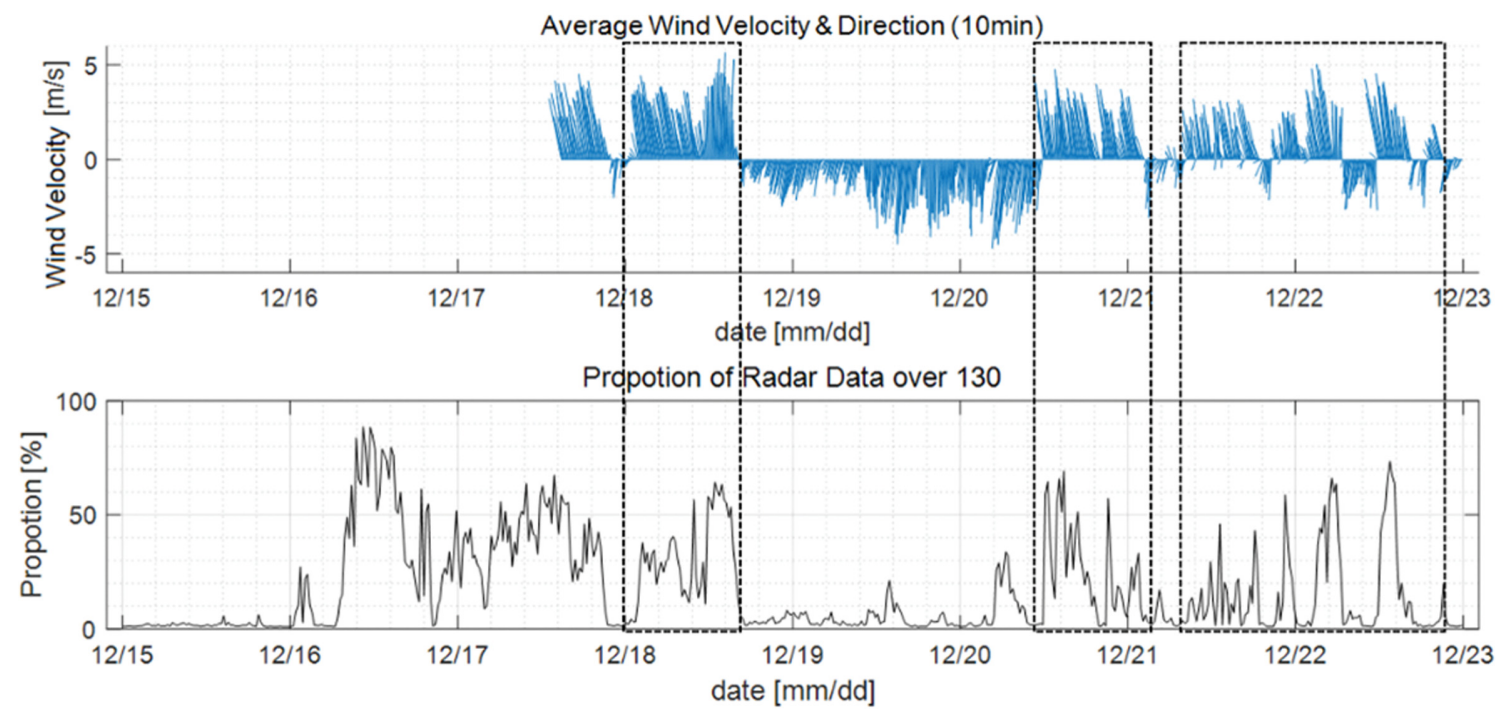

Fig. 10. Time series of the wind velocities bar and $R_{\text {vallk }}$.

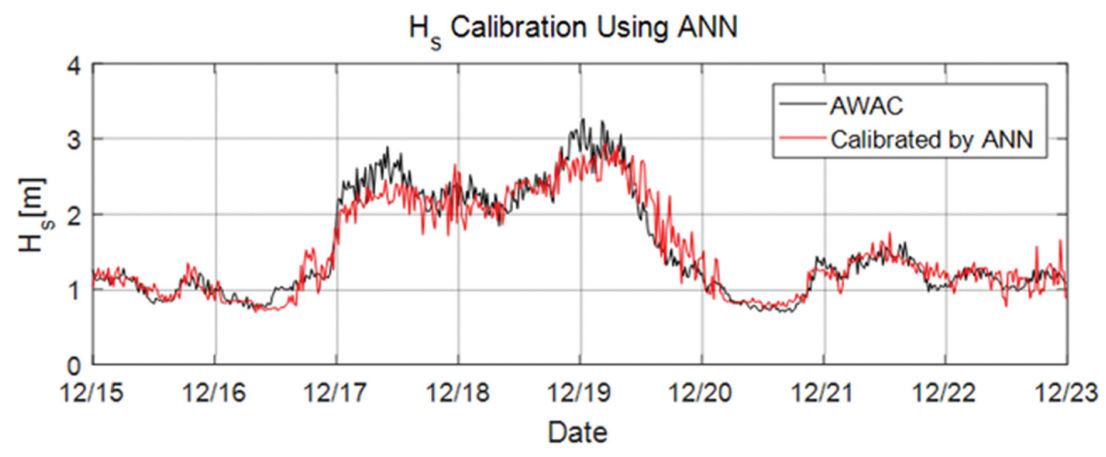

Fig. 11. Time series of the significant wave heights using ANN compared with those of AWAC. 
level and scanned the sea surface of radius from $450 \mathrm{~m}$ to $1,218 \mathrm{~m}$. The data used for the analysis had been obtained from December 15 to December 23, 2014. The radar antenna was rotating for 80 seconds with 24 rpm every 20 minutes to scan the sea surface images.

We compared the significant wave heights estimated by the X-band radar system with Hs measured by AWAC. For the case where Hs was estimated by $\sqrt{S N R}$ alone, Hs was significantly under-estimated when there was low local wind speed and wind direction is blowing from land to seaward. This is the case when poor Bragg resonance occurs on the smooth sea surfaces without ripples. In order to improve the accuracy of Hs, we incorporate peak periods $\left(T_{P}\right)$ in the estimation of Hs. It is because $T_{P}$ was not influenced by local wind condition. Accuracy of estimation of Hs using $\sqrt{S N R}$ and $T_{P}$ improved with RMSE of $0.29 \mathrm{~m}$, a maximum error of $0.99 \mathrm{~m}$, and $R^{2}$ of 0.79 .

For further improvement of accuracy of Hs, we adopted ANN with feedforward backpropagation network using 3 parameters; $\sqrt{S N R}, T_{P}$ and $R_{\text {valk }}$. Parameter $R_{\text {vall }}$ is varying with wind speed and direction. ANN algorithm with 3 parameters yields a better estimation of Hs with RMSE of $0.22 \mathrm{~m}$, a maximum error of $0.80 \mathrm{~m}$, and $R^{2}$ of 0.89 .

\section{Acknowledgment}

This study was performed by projects of 'Investigation of large swell waves and rip currents and development of the disaster response system (No. 20140057)' sponsored by the Ministry of Oceans and Fisheries.

\section{References}

Ahn, K., Chun, J. and Cheon, S.H. (2014). New calibration method applicable to significant wave heights obtained by X-band radar. Coastal Engineering Proceedings, (34), 15-15.

Ahn, K., Oh, C.Y. and Chun, H. (2015). Algorithm for detection of current and water-depth using X-band marine radar. Procedia Engineering, 116, 818-823.

Alpers, W. and Hasselmann, K. (1982). Spectral signal to clutter and thermal noise properties of ocean wave imaging synthetic aperture radars. International Journal of Remote Sensing, 3(4), 423-446.

Borge, J.N. and Soares, C.G. (2000). Analysis of directional wave fields using $\mathrm{X}$-band navigation radar. Coastal Engineering, 40(4), 375-391.

Nieto Borge, J., RodrÍguez, G.R., Hessner, K. and González, P.I. (2004). Inversion of marine radar images for surface wave analysis. Journal of Atmospheric and Oceanic Technology, 21(8), 1291-1300.

Young, I.R., Rosenthal, W. and Ziemer, F. (1985). A three-dimensional analysis of marine radar images for the determination of ocean wave directionality and surface currents. Journal of Geophysical Research: Oceans, 90(C1), 1049-1059.

Received 15 December, 2020

Revised 22 December, 2020

Accepted 22 December, 2020 